\title{
LandCover6k: Global anthropogenic land-cover change and its role in past climate

\author{
Marie-José Gaillard ${ }^{1}$ and LandCover6k Interim Steering Group members ${ }^{2}$
}

\begin{abstract}
There is today a general understanding of the need for powerful climate models to inform societies on the climate's possible development in the future. Climate models help us to understand the climate system as a whole and envisage our future. They have existed for many decades and have developed progressively into very complex Earth system models (ESMs) in which the atmosphere, the ocean and land-surface processes are coupled. Although already powerful, many of these ESMs are still under development. By using a model-data comparison approach, i.e. comparing model outputs with actual climate data over decades, centuries, and millennia back in time (paleoclimate data), both model outputs and paleodata can be better understood and evaluated, which also contributes to model improvements.
\end{abstract}

Land cover (here referring essentially to veg etation cover, but also bare soils and rocks) is an inherent part of the climate system. Natural, primarily climate-driven vegetation and ecosystem processes interact with human land use to determine vegetation cover on earth and its development through time. The resulting land-surface properties feed back to climate by modulating exchanges of energy, water, and greenhouse gases with the atmosphere through biogeochemical feedbacks (affecting sources and sinks of greenhouse gases, aerosols, pollutants, and other gases) and biogeophysical feedbacks (affecting heat and water fluxes, and wind direction and magnitude). The sum of these feedbacks may be either positive, i.e. amplifying changes in climate (e.g. amplifying a warming or a cooling trend), or negative, i.e. slowing trends in climate (e.g. slowing a warming or a cooling trend). Biogeochemical feedbacks, especially involving the carbon cycle, have received particular attention. However, biogeophysical feedbacks can have an effect of comparable magnitude; but because biogeophysical feedbacks generally operate at the regional scale they may be missed or underestimated at the relatively coarse resolution of Global ESMs. These feedbacks still represent a major source of uncertainty in climate projections under rising greenhouse gas concentrations. Therefore, the incorporation of dynamic vegetation into ESMs currently is one of the high priorities among climate modelers.
The effects of anthropogenic burning and deforestation on past global climate are not fully understood yet, and the question of whether humans had more impact than previously assumed on climate in prehistory (the Ruddiman hypothesis; Ruddiman 2003) is still a matter of debate. As long as the effects of land-use changes are not properly understood, mitigation strategies such as afforestation to sequester $\mathrm{CO}_{2}$ and cool the climate might be erroneous. Moreover, the scenarios of past ALCCs often used in climate modeling, such as HYDE (Klein Goldewijk et al. 2011), the KK scenarios (Kaplan et al. 2009), and others (e.g. Pongratz et al. 2008), show large differences between each other (Gaillard et al. 2010). Therefore, climate modeling in paleo-mode taking into account anthropogenic land-cover

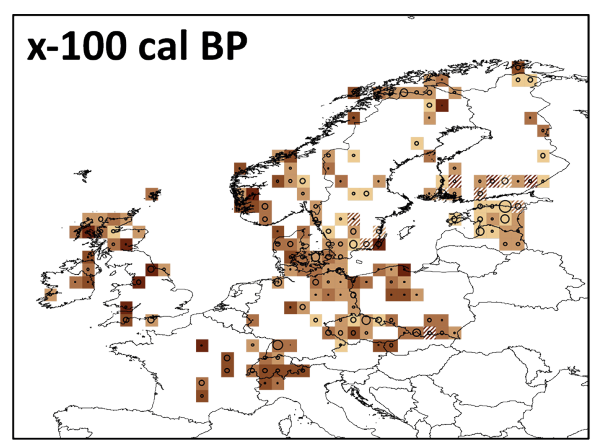

change (ALCC) is seriously hampered. Thus, there is an imminent need for independent descriptions of past vegetation cover based on empirical data and an improved ALCC history at regional scales and globally. Such independent descriptions can be provided by pollen-based quantitative reconstructions of past vegetation cover such as those recently achieved for a large part of Europe (Trondman et al., in press; Fig. 1).

\section{The methodological starting point for LandCover6k}

Objective, quantitative long-term records of past vegetation cover changes are, however, still limited globally. Although biomization of pollen data (Prentice et al. 1996) has become a robust tool to reconstruct the distribution of biomes and their boundaries over the
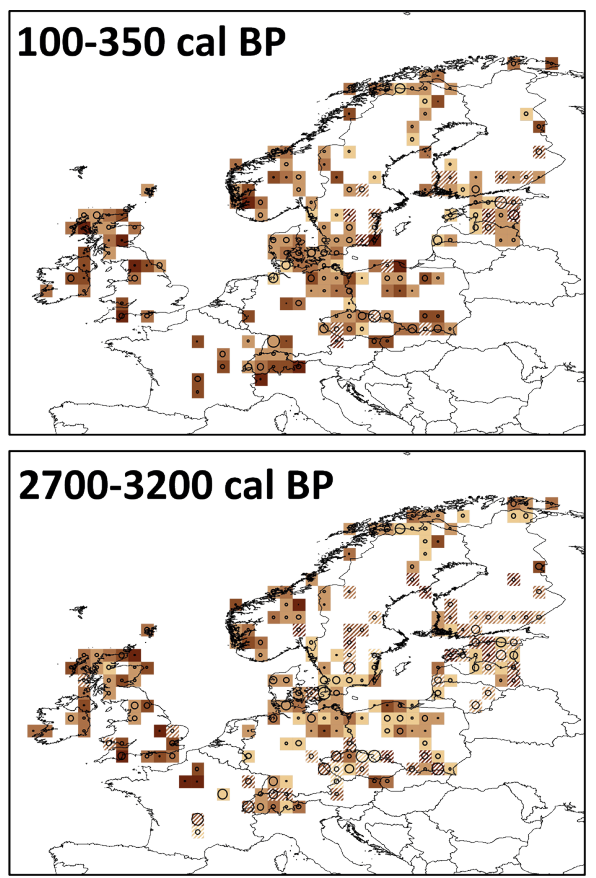

Figure 1: Grid-based REVEALS estimates for the plant functional type (PFT) grassland (GL) for three Holocene time-windows. The scale is percentage cover, with the different colors indicating different percentage intervals: $>0-10 \%$ in $2 \%$ intervals, $10-20 \%$ in a $10 \%$ interval, and $20-100 \%$ in $20 \%$ intervals. The category 0 (grey) corresponds to the grid cells with pollen records but no pollen data for the actual PFT and, therefore, no REVEALS estimates. The category $>0-2$ corresponds to REVEALS estimates different from zero (can be less than $1 \%$ ) up to $2 \%$. The uncertainties of PFT REVEALS estimates are shown by circles of various sizes in each grid cell with an estimate. The circles represent the coefficient of variation ( $\mathrm{CV}$; the standard error divided by the REVEALS estimate). When SE $\geq$ REVEALS estimate, the circle fills the entire grid cell and the REVEALS estimate is considered unreliable. This occurs mainly where REVEALS estimates are low. GL (all most common herbs): Artemisia species, Cyperaceae, Filipendula species, Poaceae (Gramineae), Plantago lanceolata, Plantago media, Plantago montana, Rumex acetosa-type (several species). Modified from Trondman et al. (in press). 
globe, the methodology does not provide quantitative reconstructions of plant cover, e.g. fractions of deforested land or fractions of conifer trees versus deciduous trees. Unti a few years ago, it was not possible to translate fossil pollen found in lake sediments or peat into a quantitative description of the past vegetation. However, Sugita (2007) developed an algorithm for inverse modeling of the relationship between pollen and vegetation (Regional Estimates of VEgetation Abundance from Large Sites; REVEALS) that makes it possible to translate fossil pollen data into vegetation cover at regional spatial scales. The LandCover6k working group aims to capitalize on the established REVEALS methodology in a large globally coordinated effort.

Scientifically, LandCover6k also builds on the European research project LANDCLIM (LAND cover - CLIMate interactions in NW Europe during the Holocene; Gaillard et al. 2010). This project applied a model-data comparison scheme that integrated a dynamic vegetation model (LPJGUESS), a regional climate model (RCA3), and the REVEALS model. The results indicate that past human-induced deforestation from Neolithic time (6 ka BP) did indeed have positive and negative biogeophysical feedbacks of $+/-1^{\circ} \mathrm{C}$ on the regional climate; the sign of the feedback varies between regions and seasons (Strandberg et al. 2014).

Other LANDCLIM results on which LandCover6k will build include the existing reconstructions of land cover over large parts of Europe during five time windows of the Holocene (Trondman et al., in press; Fig. 1) and new spatial statistical models to turn REVEALS reconstructions into spatially continuous maps of past land cover (Pirzamanbein et al. 2014; Fig. 2).

\section{LandCover6k's ambitions and strategy}

The ultimate goal of LandCover6k is to produce useful outputs for ecologists, Earth system scientists, conservation bodies, landuse managers, and policy-makers. Broken down into specific goals, the working group aims to:

- produce pollen-based land-cover reconstructions for regions of the world where human impact has been particularly intense over the Holocene prior to AD 1500 , i.e. North America, South America, Europe, Africa, Asia (China and India in particular), and Oceania (Australia, New Zealand, and other Pacific islands).

- evaluate the existing ALCC scenarios with the combined information from the pollen-based reconstructions, archeological and historical data, and other evidence of human-induced land-cover change such as paleofire reconstructions.

- improve the ALCC models and produce spatially continuous land-cover descriptions íntegrating the REVEALS-based reconstructions, biomization, dynamic vegetation modeling, ALCC modeling and spatial statistical modeling. We strive

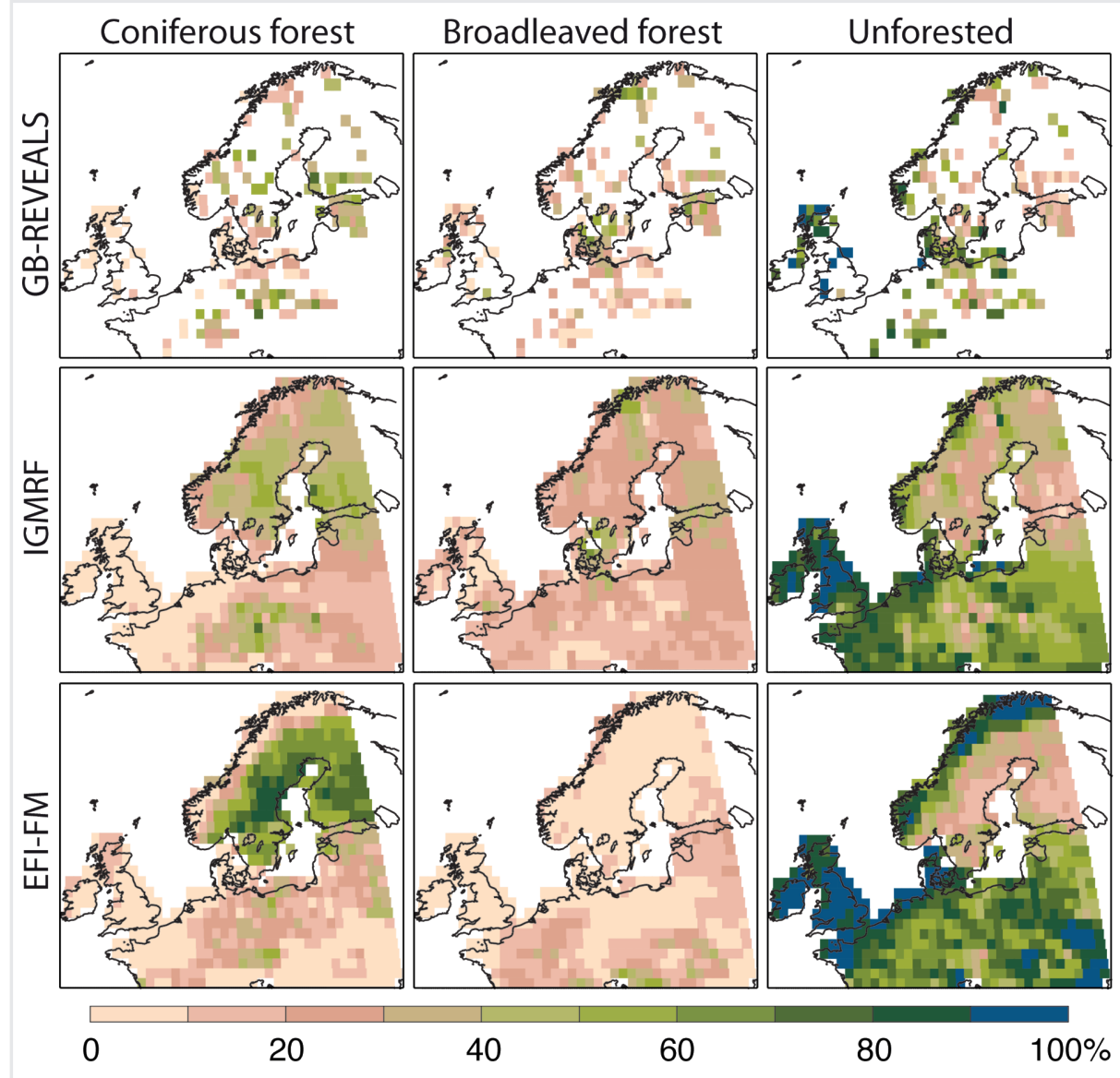

Figure 2: Reconstructions of proportion (\% cover) of the three land-cover types coniferous forest, broadleaved forest and unforested for the $0.05 \mathrm{ka}$ time window (modified from Pirzamanbein et al. 2014). From top to bottom the pollen-based REVEALS estimates, the reconstruction from the intrinsic Gaussian Markov Random Field model (IGMRF), and the present day land-cover data extracted from the forest map of Europe compiled by the European Forest Institute (EFI-FM). For details, see text and Pirzamanbein et al. (2014).

to achieve this final product within six years from now.

The ambitious and challenging plan of Land Cover6k requires a large, well-organized group of devoted scientists. The group is coordinated by experts in the various disciplines and by one or two co-leaders for each of the six regional subgroups.

The tasks of the regional subgroups will be to:

- compile the fundamental information needed to produce pollen-based REVEALS reconstructions of past land cover, i.e. obtain new pollen records of past anthropogenic vegetation change, develop pollen databases, and estimate pollen productivities and fall speeds of the regionally prevailing plant taxa.

- develop datasets of archeological and historical information on past land cover.

- achieve as many REVEALS reconstructions as possible for each region.

- evaluate the REVEALS reconstructions by comparison with archeological and historical datasets (AHDs).

- evaluate the ALCCs for each region on the basis of the REVEALS reconstructions and AHDs.

LandCover6k welcomes new members, particularly archeologists and historians, who are interested in this kind of work and feel they can provide useful information and make a contribution to the group's goals. A launch meeting is planned in Paris, France from 18-20 February 2015, which aims to determine the organization, structure, and milestones of the group for 2015-2017. For more information visit the LandCover6k website at: www.pages-igbp.org/workinggroups/ landcover6k

\section{AFFILIATIONS}

'Department of Biology and Environmental Science, Linnaeus University, Kalmar, Sweden

${ }^{2}$ See list of Interim Steering Group members at: www.pages-igbp.org/workinggroups/landcover6k/people

CONTACT

Marie-José Gaillard: marie-jose.gaillard@Inu.se REFERENCES

Gaillard M-J et al. (2010) Clim Past 6: 483-499 Klein Goldewijk K et al. (2011) Glob Ecol Biogeogr 20: 73-86

Kaplan JO et al. (2009) Quat Sci Rev 28: 3016-3034 Pirzamanbein B et al. (2014) Ecol Complexity 20: 127-141 Pongratz J et al. (2008) Glob Biogeochem Cycles 22, doi:10.1029/2007GB003153

Prentice IC et al. (1996) Clim Dyn 12: 185-194 Ruddiman WF (2003) Clim Change 61: 261-293 Strandberg G et al. (2014) Clim Past 10: 661-680 Sugita S (2007) Holocene 17: 229-241 Trondman A-K et al. (in press) Glob Chang Biol, doi:10.1111/gcb.12737 